\title{
RELATIONSHIPS AMONG INDICATORS OF FITNESS, FATNESS AND CARDIOVASCULAR DISEASE RISK FACTORS IN ADOLESCENTS
}

\author{
${ }^{1}$ Duncan Strachan Buchan, ${ }^{1}$ John Young, ${ }^{2}$ Stephen-Mark Cooper, \\ ${ }^{3}$ Robert Malina, ${ }^{4}$ John Cockcroft and ${ }^{1}$ Julien Stephen Baker \\ ${ }^{1}$ Institute for Clinical Exercise and Health Science, School of Science, \\ University of the West of Scotland, Hamilton, ML3 0JB, Scotland, UK \\ ${ }^{2}$ Cardiff School of Sport, Cardiff Metropolitan University, \\ Cyncoed Campus, Cyncoed Road, Cardiff, CF23 6XD, Wales, UK \\ ${ }^{3}$ Department of Kinesiology and Health Education, The College of Education, \\ The University of Texas at Austin, 1 University Station-D3700, Austin, TX 78712-0360, USA \\ ${ }^{4}$ Department of Cardiology, Wales Heart Research Institute, \\ University of Wales College of Medicine, Heath Park, Cardiff, CF14 4XN, UK
}

Received 2012-07-02, Revised 2012-08-02; Accepted 2012-08-02

\begin{abstract}
In adults, fatness and low cardiorespiratory fitness are associated with a higher prevalence of chronic disease risk and mortality. The association between measures of physical fitness and fatness upon cardiovascular risk in youth, however, is less clear. The effects of adiposity and physical fitness upon cardiovascular disease risk factors in youth are receiving increasing attention but studies that have examined their independent associations are sparse. The purpose of this study thus was to investigate relationships among cardiovascular disease risk factors, four indicators of physical fitness and three indicators of fatness in a healthy adolescent cohort. Forty-eight boys and ten girls, 16.4 \pm 0.7 years, volunteered to participate in this cross-sectional study. Measurements included Blood Pressure (BP), three indicators of fatness and fat distribution Body Mass Index (BMI), waist-to-hip ratio, waist circumference), four measures of physical fitness (aerobic fitness, muscular fitness, sprinting speed, agility), weekly food intake and Physical Activity (PA) levels. Metabolic CVD risk factors included Total Cholesterol (TC), insulin, High-Density Lipoprotein (HDL), Low-Density Lipoprotein (LDL), high-sensitivity C-Reactive Protein (CRP), glucose, fibrinogen, interleukin-6, adiponectin, triglyceride and Plasminogen Activator Inhibitor-1 (PAI-1). Relationships between cardiorespiratory fitness and adiponectin $(r=0.443)$ and between muscular power and glucose $(r=0.430)$ were significant and moderate. Significant inverse correlations were also noted between adiponectin, sprint $(r=-0.456)$ and agility $(r=$ $0.399)$ performance. Adiponectin was also significantly and inversely correlated with waist circumference $(r=$ - 0.514) and BMI $(r=-0.434)$. From the regression models, a significant percentage of the variance in cardiorespiratory fitness, muscular fitness, agility and sprint performance (about 74, 53, 46 and 59\%) was explained by traditional covariates. The results indicate that adiponectin is independently associated with different indicators of physical fitness and adiposity. Future studies may need to consider implementing interventions that improve all measures of physical fitness to ensure enhanced CVD risk profiles of youth.
\end{abstract}

Keywords: Youth, Physical Fitness, Metabolic Profile, C-Reactive Protein (CRP), High-Density Lipoprotein (HDL), Blood Pressure (BP), Body Mass Index (BMI)

\section{INTRODUCTION}

Findings from the recent Scottish Health Survey noted that $15 \%$ of the adult population and $4 \%$ of those $16-24$ years of age had one or more Cardiovascular Disease (CVD) risk factors (TSG, 2008). Though CVD events are more likely to occur from middle age onwards (Raitakari et al., 2003), risk factors are increasingly prevalent in University of the West of Scotland, Hamilton, ML3 0JB, Scotland, UK 
childhood (Eisenmann, 2007). CVD risk factors such as obesity, poor lipid status and hypertension also tend to track from childhood and adolescence into adulthood and are significant contributors to mortality in the Western world (Raitakari et al., 2003; Tam et al., 2010). Hence, prevention of unfavourable health profiles at an early age is warranted.

Participation in Physical Activity (PA) tends to decline during adolescence (Lubans et al., 2008). The general leaving age from secondary school in Scotland is 16 years. Of relevance, leaving secondary school is one factor that negatively affects PA levels and sport participation in both sexes (Lubans et al., 2008). Yet, relatively little is known about the health status of adolescents as they approach the age where they can opt to leave formal education. In adults, physical inactivity, weight status and low cardiorespiratory fitness are associated with higher prevalence of chronic disease risk and mortality (Raitakari et al., 2003). The association between fitness, fatness and CVD risk in adolescents, however, is less clear. Though obesity and overweight are associated with increased CVD risk in adolescents (Eisenmann, 2007), moderate to high levels of cardiorespiratory fitness is also associated with reduced clustering of CVD risk factors (Artero et al., 2011). Though poor cardiorespiratory fitness levels and excess adiposity often occur together (Eisenmann, 2007), the relative importance of each to health status requires further study.

Potential independent effects of adiposity and cardiorespiratory fitness on CVD risk factors are receiving increasing attention (Artero et al., 2011; MartinezGomez et al., 2012). At present, the available literature that has examined associations between physical fitness and CVD risk in youth has largely focused on cardiorespiratory fitness. Studies that have examined the independent associations between other indicators of physical fitness and CVD risk factors are sparse. Increasing evidence, however, suggests the potential importance of monitoring several indicators of physical fitness in evaluating the health status of youth populations (Artero et al., 2011; Martinez-Gomez et al., 2011). Physical fitness is not a unitary concept; it includes muscular, cardiorespiratory, motor, metabolic and morphological components (Ortega et al., 2008).

Understanding the relative importance of relationships between fatness and components of physical fitness and CVD risk factors is potentially important in the design of public health strategies aimed at improving unfavourable CVD risk profiles. Four health-related components of physical fitness have been suggested: cardiorespiratory, muscular, speed and agility (Ortega et al., 2008).

The aim of this study was to examine relationships among CVD risk factors and four components of physical fitness (aerobic [cardiorespiratory], muscular [power], speed and agility) and three indicators of fatness (waist circumference, Body Mass Index (BMI) and waist-to-hip ratio) in a cross-sectional sample of
Scottish adolescents. The study also examined whether the relationships were independent or if they were related to blood markers associated with CVD risk. To our knowledge, this is the first study to analyze the independent effects of covariates on measures of physical fitness and fatness.

\section{MATERIALS AND METHODS}

A total of 58 participants (48 boys and 10 girls, $16.4 \pm 0.7$ years of age) volunteered for the study. Both the school and the parents approved the study protocol prior to the study and informed consent and assent was received from parents and participants. Ethical approval was received from the University of the West of Scotland Ethics committee. All participants were assured of anonymity and were free to withdraw from the study at any time. The participants attended a public High School of which, $16.5 \%$ of the catchment area was eligible for free school meals (TSG, 2010). According to the Scottish Index of Multiple Deprivation 2009, a rank of 1 is most deprived and 6,505 is least deprived. The school's catchment area had a rank of 1,153 (TSG, 2009). As such, participants were designated as low socio-economic status.

\subsection{Physical and Physiological Measures}

Body mass was measured to the nearest $0.1 \mathrm{~kg}$ using calibrated electronic weighing scales (Seca 880, Digital Scales, Seca Ltd, Birmingham, UK). Height was measured to the nearest $0.001 \mathrm{~m}$ (Seca Stadiometer, Seca Ltd, Birmingham, UK) with participants standing upright either in barefoot or stockings and light indoor clothing. The Body Mass Index (BMI) was calculated. Waist circumference was measured at the level midway between the lower ribs and the iliac crest. Hip circumference was measured at the widest point between the buttocks and the iliac crest as described previously (Buchan et al., 2011a). The waist-to-hip ratio was calculated as an index of relative fat distribution (Ledoux et al., 1997). A self-report questionnaire for stage of Pubic Hair (PH) development based on the criteria of (Tanner, 1963) was used to estimate sexual maturation status. Systolic Blood Pressure (SBP) and Diastolic Blood Pressure (DBP) were measured with an automated monitor (Omron M10-IT Blood Pressure Monitor HEM-7080IT-E, Omron Healthcare UK Ltd, Milton Keynes, UK) after each participant sat quietly for $10 \mathrm{~min}$.

Full details of procedures used to measure cardiorespiratory fitness, muscular fitness, sprinting speed and agility have been discussed previously (Buchan et al., $2010 ; 2011 \mathrm{~b})$. Cardiorespiratory fitness was estimated using the $20 \mathrm{~m}$ Multistage Shuttle run Fitness Test (20MSFT) (Leger et al., 1988). The Counter Movement Jump (CMJ) was used to measure muscular fitness (power); height of the jump was measured using the 
Optojump system (Microgate, Bolzano, Italy) after a standardized warm-up. Sprint (running) speed over $10 \mathrm{~m}$ was measured using an electronic sprint timer with photoelectric sensors (Polifemo Radio Light- Microgate, Italy). Agility was measured using the 505-agility test (Draper and Lancaster, 1985) using two photoelectric sensors (Polifemo Radio Light- Microgate, Italy) placed 5 $\mathrm{m}$ from the starting line and $5 \mathrm{~m}$ from a designated turning point. All fitness measures were randomly assigned and data was recorded following familiarization periods; data collection time was standardised (morning testing) to control for diurnal variation. All measures were taken following $48 \mathrm{~h}$ of no physical activity.

Daily food intake was monitored using a validated, self-reported seven-day food diary (McCance, 2002) and food frequency questionnaire. Participants were instructed to complete the food diary and record everything that they ate and drank over a specified seven-day period. Returned food diaries and questionnaires were inspected and when necessary, clarification of responses was confirmed by interview with participants. During this time, participants were instructed to continue their normal eating and drinking behaviours. Collated data were analyzed using nutritional analysis software by Health Options Ltd (Nutri Check, Health Options Ltd, Cirencester, Gloucester, UK). Average daily kilocalories $(\mathrm{kcal} / \mathrm{d})$, percentage of total fat (total fat \%) and saturated fat (sat fat $\%$ ) were calculated.

All participants completed a validated Physical Activity Questionnaire for Adolescents (PAQ-A) (Kowalski et al., 1997) which required them to recall their PA behaviours from the previous 7 days. The questionnaire was completed during scheduled class time and required no longer than $30 \mathrm{~min}$.

\subsection{Biochemical Measures}

Blood samples were collected between 9:00 am and 11:00 am after an overnight fast. Prior to sampling, participants were instructed to sit quietly for a period of at least $30 \mathrm{~min}$ to control for plasma volume shifts. A team of qualified phlebotomists, experienced in paediatric sampling techniques, collected blood samples from the participants. Blood samples were obtained from an antecubital vein and collected in a BD Vacutainer plasma tube. Plasma was isolated by centrifugation at 3 $500 \mathrm{rpm}$ for $10 \mathrm{~min}$ and then frozen at $-80^{\circ} \mathrm{C}$ within two $\mathrm{h}$ of collection. Samples were analyzed for Total Cholesterol (TC), insulin, HDL, LDL, CRP, glucose, fibrinogen, IL-6, adiponectin, triglyceride and PAI-1. All blood analyses were performed using standard procedures. Total cholesterol and triglyceride were measured by enzymatic methods (Randox, Co. Antrim, UK) and a Camspec M107 spectrophotometer (Camspec, Leeds, UK). Concentration of HDL was determined after precipitation of very low density and low-density lipoproteins by the addition of phosphotungstic acid in the presence of magnesium ions. The Friedewald et al. (1972) formula was used to calculate LDL concentration. Glucose was measured with the glucose oxidase method (Randox, Co. Antrim, UK) and analyzed using a Camspec M107 spectrophotometer (Camspec, Leeds, UK). Insulin was analyzed with commercially available immunoassay kits (ALPCO, Salem, NH, USA) and a Camspec M107 spectrophotometer (Camspec, Leeds, UK). Fibrinogen concentration was analyzed using commercially available immunoassay kits (ALPCO, Salem, NH, USA) and a MRX microplate reader (Dynatech Laboratories, MA, USA). Concentrations of IL-6, CRP, adiponectin and PAI-1 were measured with specific ELISA kits ( $R$ and D Systems, Abingdon, UK) and a MRX microplate reader (Dynatech Laboratories, MA, USA). All samples were measured in duplicate.

\subsection{Statistical Analysis}

Participant characteristics are presented as mean \pm SD. Partial correlations were calculated between seven Dependent Variables (DV) and thirteen Independent Variables (IV). Covariates included gender, maturity status (PH), PA level, total dietary fat, total dietary saturated fat and $\mathrm{kcal} / \mathrm{d}$. The DV consisted of indices of physical fitness and adiposity while the IV consisted of SBP and DBP and 11 metabolic risk factors of CVD.

Multiple linear regression analysis was used to determine the combined and independent, associations between the DV and gender, maturity status, PA level, total dietary fat, total dietary saturated fat and $\mathrm{kcal} / \mathrm{d}$. In order to analyse the relative contribution of each of the variables to the DV, all the variables were standardized (z-scores). Multiple regression analysis was applied using the standardised variables to identify how much variance in the DV identified was accounted for by the IV. As we were not using regression methods to model these scores in terms of prediction, we included the results for both genders collectively. As this was likely to increase the heterogeneity of the variables of interest, we suspected this would produce larger correlations from our data given the sensitivity of correlation and regression methods to subject heterogeneity. The b-values from the coefficients table were used to determine the individual contribution of each IV to the DV. As such modelling is dependent upon residuals being both random and normally distributed, residuals were saved while running the regression analyses and normality was subsequently confirmed. All statistical analyses was performed using the Statistical Package for the Social Sciences (version 19; SPSS Inc., Chicago, IL, USA) and values of $p<0.05$ were considered statistically significant.

\section{RESULTS}

Statistical summaries for all subject characteristics are summarized in Table 1 and 2. Pubertal status was as 
follows: boys-PH3, 10; $\geq$ PH4, 38; girls-PH2, 2; $\geq$ $\mathrm{PH} 4,8$. Overall, $25 \%$ of the sample was overweight and $2 \%$ was underweight, the remainder was normal or healthy weight. Partial correlations for measures of physical fitness and fatness with individual CVD risk factors after adjustments for gender, pubertal status, PA level and dietary indices are summarized in Table
3. Cardiorespiratory fitness was positively associated with adiponectin $(\mathrm{r}=0.443, \mathrm{p}=0.027)$ whereas CMJ performance was positively associated with fasting glucose concentration $(\mathrm{r}=0.430, \mathrm{p}=0.032)$. Agility and $10 \mathrm{~m}$ sprint performance were both positively associated with adiponectin $(\mathrm{r}=0.486, \mathrm{p}=0.014 ; \mathrm{r}=$ 0.399 , $0.048)$.

Table 1. Means \pm SD for anthropometric, dietary and physiological characteristics of all participants $(\mathrm{N}=58)$

\begin{tabular}{|c|c|c|}
\hline Variables (units) & Mean \pm SD & $95 \% \mathrm{CI}$ \\
\hline Age (years) & $16.4 \pm 0.70$ & $16.2-16.6$ \\
\hline Gender, Boys/Girls & $48 / 10000$ & \\
\hline Stature $(\mathrm{cm})$ & $171.4 \pm 8.50$ & 169.2 to 173.60 \\
\hline Body mass (kg) & $65.5 \pm 9.20$ & 63.1 to 67.900 \\
\hline BMI $\left(\mathrm{kg} \mathrm{m}^{-2}\right)$ & $22.3 \pm 2.90$ & 21.5 to 23.100 \\
\hline Waist circumference $(\mathrm{cm})$ & $75.1 \pm 5.95$ & 73.5 to 76.700 \\
\hline Waist-to-hip ratio & $0.8 \pm 0.10$ & 0.77 to 0.830 \\
\hline PAQ-A & $2.1 \pm 0.6$ & 1.9 to 2.3000 \\
\hline Total fat $(\mathbf{\%})$ & $35.8 \pm 4.5(n=54)^{*}$ & 34.6 to 37.000 \\
\hline Sat fat $(\%)$ & $14.2 \pm 2.5(n=54)^{*}$ & 13.5 to 14.900 \\
\hline $\mathrm{kCal} / \mathrm{d}$ & $1637.7 \pm 417.8(n=54)^{*}$ & 1523.7 to 1751.7 \\
\hline $\mathrm{SBP}(\mathrm{mm} \mathrm{Hg})$ & $112 \pm 10$ & 109 to 1150000 \\
\hline DBP (mm Hg) & $67 \pm 7$ & 65 to 6900000 \\
\hline Cardiorespiratory fitness (shuttles) & $79 \pm 24$ & 73 to 8500000 \\
\hline CMJ $(\mathrm{cm})$ & $32.2 \pm 5.8$ & 30.7 to 33.700 \\
\hline Agility (s) & $2.5 \pm 0.3$ & 2.4 to 2.6000 \\
\hline $10 \mathrm{~m}$ sprint $(\mathrm{s})$ & $1.9 \pm 0.2$ & 1.8 to 2.0000 \\
\hline
\end{tabular}

where, $n \neq$ denoted number, actual sample number is presented in parenthesis

Table 2. Means $\pm \mathrm{SD}$ for CVD risk factors for all participants

\begin{tabular}{lcc}
\hline CVD risk factor & \multicolumn{1}{c}{ Mean $\pm \mathrm{SD}$} & $95 \%$ CI \\
\hline Adiponectin $(\mathrm{ng} / \mathrm{mL})$ & $7915 \pm 376(\mathrm{n}=53)^{*}$ & 7811 to 8019 \\
CRP $(\mathrm{mg} / \mathrm{L})$ & $1.7 \pm 2.7(\mathrm{n}=53)^{*}$ & 1.0 to 2.4 \\
Fibrinogen $(\mathrm{mg} / \mathrm{dL})$ & $154.8 \pm 11.7(\mathrm{n}=45)^{*}$ & 151.3 to 158.3 \\
IL-6 $(\mathrm{pg} / \mathrm{mL})$ & $6.3 \pm 18.2(\mathrm{n}=49)^{*}$ & 1.1 to 11.5 \\
LDL $(\mathrm{mmol} / \mathrm{L})$ & $1.9 \pm 0.1(\mathrm{n}=42)^{*}$ & 1.67 to 1.73 \\
HDL $(\mathrm{mmol} / \mathrm{L})$ & $1.6 \pm 0.1(\mathrm{n}=52)^{*}$ & 1.57 to 1.63 \\
Total Cholesterol $(\mathrm{mmol} / \mathrm{L})$ & $3.9 \pm 0.2(\mathrm{n}=52)^{*}$ & 3.8 to 4.0 \\
PAI-1 $(\mathrm{ng} / \mathrm{mL})$ & $22.3 \pm 1.8(\mathrm{n}=52)^{*}$ & 21.8 to 22.8 \\
Glucose $(\mathrm{mmol} / \mathrm{L})$ & $4.7 \pm 1.2(\mathrm{n}=52)^{*}$ & 4.4 to 5.0 \\
Insulin $(\mu \mathrm{IU} / \mathrm{mL})$ & $6.1 \pm 0.7(\mathrm{n}=46)^{*}$ & 5.9 to 6.3 \\
Triglyceride $(\mathrm{mmol} / \mathrm{L})$ & $0.8 \pm 0.04(\mathrm{n}=52)^{*}$ & 0.79 to 0.81 \\
\hline
\end{tabular}

$*_{\mathrm{n}}=$ sample number available for each variable

Table 3. Partial correlations (r, adjusted for sex, pubertal stage, physical activity levels and dietary indices) for measures of physical fitness and fatness

\begin{tabular}{|c|c|c|c|c|c|c|c|c|c|c|c|c|c|}
\hline & Glucose & Triglycerides & $\begin{array}{l}\text { Total } \\
\text { s cholesterol }\end{array}$ & HDL-C & LDL-C & Adiponectin & Fibrinogen & IL-6 & Insulin & PAI-1 & CRP & $\begin{array}{l}\text { Systolic } \\
\text { BP }\end{array}$ & $\begin{array}{l}\text { Diastolic } \\
\text { BP }\end{array}$ \\
\hline Cardiorespiratory & 0.057 & -0.201 & -0.060 & -0.033 & 0.008 & 0.443 & 0.129 & 0.217 & -0.323 & 0.216 & -0.130 & 0.136 & -0.620 \\
\hline Fitness & -0.788 & -0.334 & -0.775 & -0.874 & -0.969 & $(0.027)^{*}$ & -0.539 & -0.297 & -0.115 & -0.299 & -0.950 & -0.516 & -0.770 \\
\hline \multirow[t]{2}{*}{ CMJ } & 0.430 & 0.030 & 0.590 & 0.251 & -0.53 & 0.197 & 0.033 & 0.136 & -0.260 & 0.032 & -0.026 & 0.151 & 0.212 \\
\hline & $(0.032)^{*}$ & -0.888 & -0.779 & -0.227 & -0.801 & -0.345 & -0.875 & -0.518 & -0.902 & -0.881 & -0.903 & -0.472 & -0.309 \\
\hline \multirow[t]{2}{*}{ Agility ${ }^{a}$} & 0.100 & -0.082 & 0.099 & 0.074 & 0.092 & 0.486 & 0.044 & 0.345 & -0.284 & 0.301 & 0.950 & 0.181 & 0.140 \\
\hline & -0.636 & -0.695 & -0.639 & -0.727 & -0.66 & $(0.014)^{*}$ & -0.834 & -0.091 & -0.169 & -0.144 & -0.653 & -0.385 & -0.505 \\
\hline \multirow[t]{2}{*}{$10 \mathrm{~m}$ sprint $^{\mathrm{a}}$} & 0.253 & -0.299 & 0.290 & 0.194 & 0.16 & 0.399 & 0.077 & 0.156 & -0.340 & 0.348 & -0.220 & 0.133 & -0.087 \\
\hline & -0.222 & $0.147)$ & -0.889 & -0.352 & -0.941 & $(0.048)^{*}$ & -0.715 & -0.455 & -0.096 & -0.088 & -0.291 & -0.526 & -0.679 \\
\hline Waist & -0.076 & 0.203 & 0.014 & -0.081 & -0.014 & -0.514 & -0.351 & -0.160 & 0.385 & -0.158 & -0.014 & -0.047 & 0.081 \\
\hline Circumference & -0.718 & -0.332 & -0.946 & -0.699 & -0.947 & $(0.009)^{* *}$ & -0.085 & -0.446 & -0.057 & -0.450 & -0.946 & -0.825 & -0.702 \\
\hline Waist--to-hip & 0.104 & -0.033 & 0.011 & 0.067 & -0.005 & -0.272 & -0.217 & 0.154 & 0.162 & -0.110 & -0.123 & -0.008 & 0.220 \\
\hline Ratio & -0.620 & -0.876 & -0.959 & -0.751 & -0.982 & -0.188 & -0.297 & -0.490 & -0.438 & -0.600 & -0.558 & -0.970 & -0.290 \\
\hline \multirow[t]{2}{*}{$\begin{array}{l}\text { BMI } \\
\text { BMI }\end{array}$} & -0.128 & 0.173 & 0.136 & -0.108 & 0.128 & -0.434 & -0.288 & -0.116 & 0.302 & -0.056 & 0.092 & -0.018 & 0.142 \\
\hline & -0.542 & -0.407 & -0.516 & -0.606 & -0.541 & $(0.030)^{*}$ & -0.162 & -0.581 & -0.142 & -0.791 & -0.662 & -0.934 & -0.499 \\
\hline
\end{tabular}

${ }^{a}$ For the Agility and $10 \mathrm{~m}$ sprint test, correlations were inverted since a lower time indicates a better performance. CMJ $=\mathrm{Counter}$ movement jump; $\mathrm{BMI}=$ body mass index. ${ }^{\mathrm{p}} \leq 0.05, * * \mathrm{p} \leq 0.01$ 
Table 4. Summary statistics for the multiple-regression analysis of measures of physical fitness, fatness, gender, maturation, physical activity levels and dietary indices $(\mathrm{N}=38)$

\begin{tabular}{lllll}
\hline & $\beta$ & $\mathrm{R}^{2}$ & Adjusted $\mathrm{R}^{2}$ & $\mathrm{P}$ value \\
\hline Cardiorespiratory & 0.889 & 0.79 & 0.737 & 0.000 \\
Fitness & & & & \\
CMJ & 0.791 & 0.626 & 0.533 & 0.000 \\
Agility & 0.751 & 0.565 & 0.456 & 0.002 \\
10 m Sprint & 0.818 & 0.669 & 0.586 & 0.000 \\
Waist Circumference & 0.365 & 0.133 & -0.083 & 0.716 \\
Waist-to-hip ratio & 0.413 & 0.170 & -0.037 & 0.564 \\
BMI & 0.362 & 0.131 & -0.086 & 0.725 \\
\hline CMJ Counter Movement Jump; $\mathrm{BMI}=$ Body Mass Index &
\end{tabular}

$\mathrm{CMJ}=$ Counter Movement Jump; BMI = Body Mass Index

Note that correlations were inverted since lower times indicate better sprint and agility performances. Waist circumference and BMI were negatively associated with adiponectin $(\mathrm{r}=-0.514, \mathrm{p}=0.009 ; \mathrm{r}=-0.434, \mathrm{p}<0.030)$.

Summary statistics of the regression models with indicators of physical fitness and fatness as the DV are shown in Table 4 . The adjusted $\mathrm{R}^{2}$ was used as a measure of the relationship between the DV and the IV's. About $74 \%$ of the variance in cardiorespiratory fitness was explained. Significant variables were $\mathrm{kcal} / \mathrm{d}(\mathrm{b}=0.313, \mathrm{P}$ $=0.018)$ and gender $(b=1.532, p=0.010)$. About $53 \%$ of the variance in $\mathrm{CMJ}$ performance was explained, but only gender was significant associated $(b=1.781, p=0.022)$. Although significant percentages of the variance in agility (46\%) and sprint (59\%) performances were explained, no specific variables were significantly associated. There were no significant associations of the three indicators of adiposity BMI, waist-to-hip ratio or waist circumference.

\section{DISCUSSION}

The purpose of this study was twofold. First, we aimed to investigate the independent relationships among several indicators of physical fitness and fatness and CVD risk factors. Secondly, we used multiple regression models to evaluate the independent, effects of traditional covariates on the variance of each fitness and fatness indicator. To our knowledge, this is the first study of its kind involving healthy Scottish adolescents. There is a dearth of information relating to the independent associations between measures of both physical fitness and adiposity with both traditional and novel CVD risk factors. It is intended that results of this investigation would suggest associated risks that can inform the design and implementation of future preventative interventions.

An important observation was the independent associations between different measures of physical fitness and adiponectin Table 3. A significant, moderate association was noted between cardiorespiratory fitness, $10 \mathrm{~m}$ sprint and agility performance and adiponectin in this sample. Though some have noted a significant association between cardiorespiratory fitness and adiponectin (Nemet et al., 2003), the authors failed to consider the effects of adiposity within their analysis and involved younger participants. Others have found no significant associations between cardiorespiratory fitness and adiponectin (McVean et al., 2009) or have found an inverse association that was not in the expected direction for health (Martinez-Gomez et al., 2010).

Adiponectin is exclusively secreted by adipokines and circulates at relatively high levels in the bloodstream unlike other adipocytiknes such as IL-6 and PAI-1. In adults, low levels of adiponectin are predictive of CVD related events and type 2 diabetes (Tjonna et al., 2008). Previous studies have also reported lower adiponectin levels in obese and overweight children (Tam et al., 2010; Valle et al., 2005) which would seem to imply that the incidence in childhood may exacerbate the prevalence of these disorders in adulthood.

Whether improvements in cardiorespiratory fitness can reduce circulating adiponectin levels is unclear in this cross-sectional study of adolescents. Significant improvements in resting adiponectin levels after 6 weeks (Kim et al., 2007) and 3 months (Balagopal et al., 2005) of physical activity interventions have been reported, but cardiorespiratory fitness of participants was not measured. Intuitively nonetheless, as both cohorts experienced significant reductions in measures of fatness (BMI, waist circumference), it is feasible that improvements in cardiorespiratory fitness would have occurred if they were evaluated, as has been demonstrated elsewhere (Kondo et al., 2006; Tjonna et al., 2008). Although these two studies (Kondo et al., 2006; Tjonna et al., 2008) involved older cohorts and longer interventions (4 to 7 months), both demonstrated significant improvements in measures of fatness. The inverse correlations between WC and BMI and adiponectin (Table 3) are consistent with the experimental studies and also with a cross-sectional study involving adolescents (Valle et al., 2005).

Results from this study found a significant moderate relationship between $10 \mathrm{~m}$ sprint and agility performances and adiponectin Table 3. Apparently only one previous study has examined associations between speed and agility with CVD risk in Dutch adolescents (Twisk et al., 2000). Unfortunately, an index of neuromotor fitness based on measures of muscular strength, flexibility, speed of movement and coordination was used so that a potentially independent effect of speed could not be partitioned. The authors did find an inverse association between a measure of fatness (sum of four skinfolds) and neuromotor fitness, but no associations were identified between neuromotor fitness and several metabolic CVD risk factors measured (TC, HDL-C, TC:HDL ratio). 
CMJ performance was also positively associated with glucose levels in the sample of Scottish adolescents. Jump tests are an indicator of muscular power among youth (Ortega et al., 2008). Other studies have either not considered or not observed an association between muscular power and glucose in healthy adolescents.

Collectively, the IV's used in the regression models predicted significant proportions of the variance in measures of physical fitness. The observation that gender was a significant predictor of cardiorespiratory fitness and CMJ performance is consistent with the literature (Mota et al., 2002; Quatman et al., 2006). Girls tend to have a higher percentage body fat than boys which can impact both cardiorespiratory fitness and jumping performances; similarly, performances of girls on many fitness tests tends to reach a plateau or perhaps decline, on average, in later adolescence (Malina et al., 2004). Previous study of the $20 \mathrm{~m}$ MSFT has shown that performances increase with age in boys more so than in girls and that performances are inversely associated with percentage body fat in both genders (Mota et al., 2002). With regards to $\mathrm{CMJ}$, boys demonstrate significant increases in performance during adolescence whereas girls do not (Malina et al., 2004).

It was somewhat surprising that $\mathrm{kCal} / \mathrm{d}$ was significantly associated with cardiorespiratory fitness. It is well known that in order to promote optimal growth and development in adolescents, energy intake must be of a sufficient quantity and quality during these informative years. However, excess unhealthy nutrient intake can be detrimental to health. Previous studies have demonstrated that the dietary habits of Scottish youth are high in total and saturated fat and indeed, poor in comparison with other European countries (Lang et al., 2006). Our findings support this assumption as $94 \%$ of our subjects consumed a diet that exceeded recommended levels of total fat intake while $98 \%$ exceeded recommended levels of saturated fat intake (data not shown). Though no relationships were noted regarding the quality of energy intake, our data seem to imply that participants are not consuming enough of the healthy and nutrient rich foods needed to promote optimal growth and development. Nonetheless, the inherent limitations of self-reported dietary measures are well established. Whether this finding reflects these limitations or indeed suggests that this cohort is undernourished is unclear.

\section{CONCLUSION}

Our results suggest that adiponectin was independently associated with several indicators of fitness and fatness. It may be that future physical activity interventions should focus not only on improving weight status but also on multiple components of physical fitness to ensure the greatest protection against unfavourable cardiometabolic risk profiles. Nonetheless, further studies are required to confirm these findings and determine the effects of physical fitness upon adipocytokines during adolescence.

\section{ACKNOWLEDGMENT}

This study was financially supported by grants from the Chief Scientist Office for Scotland and NHS Lanarkshire.

\section{REFERENCES}

Artero, E.G., J.R. Ruiz, F.B., Ortega, V. Espana-Romero and G. Vicente-Rodriguez et al., 2011. Muscular and cardiorespiratory fitness are independently associated with metabolic risk in adolescents: The HELENA study. Pediatr. Diabetes., 12: 704-712. DOI: 10.1111/j.1399-5448.2011.00769.x

Balagopal, P., D. George, H. Yarandi, V. Funanage and E. Bayne, 2005. Reversal of obesity-related hypoadiponectinemia by lifestyle intervention: A controlled, randomized study in obese adolescents. J. Clin. Endocrinol. Metab., 90: 6192-6197. DOI: 10.1210/jc.2004-2427

Buchan, D.S., S. Ollis, N.E. Thomas, N. Buchanan and S.M. Cooper et al. 2011a. Physical activity interventions: Effects of duration and intensity. Scand. J. Med. Sci. Sports, 21: 341-350. DOI: 10.1111/j.1600-0838.2011.01303.x

Buchan, D.S., S. Ollis, J.D. Young, N.E. Thomas and S.M. Cooper et al., 2011b. The effects of time and intensity of exercise on novel and established markers of CVD in adolescent youth. Am. J. Hum. Biol., 23: 517-526. DOI: 10.1002/ajhb.21166

Buchan, D.S., S. Ollis, N.E. Thomas and J.S. Baker, 2010. The influence of a high intensity physical activity intervention on a selection of health related outcomes: An ecological approach. BMC Public. Health., 10: 8-8. DOI: 10.1186/1471-2458-10-8

Draper, J.A. and M.G. Lancaster, 1985. The 505 test: a test for agility in the horizontal plane. Aust. J. Sci. Med. Sport, 17: 15-18.

Eisenmann, J.C., 2007. Aerobic fitness, fatness and the metabolic syndrome in children and adolescents. Acta Paediatrica, 96: 1723-1729. DOI: 10.1111/j.1651-2227.2007.00534.x

Friedewald, W.T., R.I. Levy and D.S. Fredrickson, 1972. Estimation of the concentration of low-density lipoprotein cholesterol in plasma, without use of the preparative ultracentrifuge. Clin. Chem., 18: 499-502.

Kim, E.S., J.A. Im, K.C. Kim, J.H. Park and S.H. Suh et al., 2007. Improved insulin sensitivity and adiponectin level after exercise training in obese Korean Youth. Obesity, 15: 3023-3030. DOI: 10.1038/oby.2007.360 
Kondo, T., I. Kobayashi and M. Murakami, 2006. Effect of exercise on circulating adipokine levels in obese young women. Endocr. J., 53: 189-195. DOI: 10.1507/endocrj.53.189

Kowalski, K.C., P.R.E. Crocker and N.P. Kowalski, 1997. Convergent validity of the physical activity questionnaire for adolescents. Pediatr. Exerc. Sci., 9: 342-352.

Lang, T., E. Dowler and D. Hunter, 2006. Review of the scottish diet action plan progress and impacts 1996-2005.

Ledoux, M., J. Lambert, B. A. Reeder and J.P. Despres, 1997. A comparative analysis of weight to height and waist to hip circumference indices as indicators of the presence of cardiovascular disease risk factors. Canadian Heart Health Surveys Research Group. CMAJ., 1: S32-S38. PMID: 9220952

Leger, L.A., D. Mercier, C. Gadoury and J. Lambert, 1988. The multistage 20 metre shuttle run test for aerobic fitness. J. Sports Sci., 6: 93-101. DOI: 10.1080/02640418808729800

Lubans, D.R., C. Foster and S.J.H. Biddle, 2008. A review of mediators of behavior in interventions to promote physical activity among children and adolescents. Prev. Med., 47: 463-470. DOI: DOI: 10.1016/j.ypmed.2008.07.011

Malina, R.M., C. Bouchard and O. Bar-Or, 2004. Growth, Maturation and Physical Activity. 2nd Edn., Human Kinetics, Champaign, ISBN-10: 0880118822, pp: 712.

Martinez-Gomez, D., G.J. Welk, M.A. Puertollano, J. Del-Campo and J.M. Moya et al., 2011. Associations of physical activity with muscular fitness in adolescents. Scand. J. Med. Sci. Sports, 21: 310-317. DOI: 10.1111/j.1600-0838.2009.01036.x

Martinez-Gomez, D., J.C. Eisenmann, J. Warnberg, S. Gomez-Martinez and A. Veses et al., 2010. Associations of physical activity, cardiorespiratory fitness and fatness with low-grade inflammation in adolescents: the AFINOS study. Int. J. Obes., 34: 1501-1507. DOI: $10.1038 /$ ijo.2010.114

Martinez-Gomez, D., J.C. Eisenmann, S. GomezMartinez, A. Veses and J. Romeo et al., 2012. Associations of physical activity and fitness with adipocytokines in adolescents: The AFINOS study. Nutr. Metab. Cardiovasc. Dis., 22: 252-259. DOI: 10.1016/j.numecd.2010.07.010

McCance, R.A., 2002. Food Standards Agency. McCance and Widdowson's The Composition of Foods. 6th Edn., Royal Society of Chemistry, Cambridge, ISBN-10: 0854044280, pp: 554.

McVean, J.J., A.L. Carrel, J.C. Eickhoff and D.B. Allen, 2009. Fitness level and body composition are associated with inflammation in non-obese children. J. Pediatr. Endocrinol. Metab., 22: 153-159. DOI: 10.1515/JPEM.2009.22.2.153
Mota, J., S. Guerra, C. Leandro, A. Pinto and J.C. Ribeiro et al., 2002. Association of maturation, sex and body fat in cardiorespiratory fitness. Am. J. Hum. Biol., 14: 707-712. DOI: 10.1002/ajhb.10086

Nemet, D., P. Wang, T. Funahashi, Y. Matsuzawa and S. Tanaka et al., 2003. Adipocytokines, body composition and fitness in children. Pediatr. Res., 53: 148-152. DOI: 10.1203/00006450-200301000-00025

Ortega, F.B., J.R. Ruiz, M.J. Castillo and M. Sjostrom, 2008. Physical fitness in childhood and adolescence: a powerful marker of healthFitness as a health marker in young people. Int. J. Obes., 32: 1-11. DOI: $10.1038 /$ sj.ijo.0803774

Quatman, C.E., K.R. Ford, G.D. Myer and T.E. Hewett, 2006. Maturation leads to gender differences in landing force and vertical jump performance: A longitudinal study. Am. J. Sports Med., 34: 806-813. DOI: $10.1177 / 0363546505281916$

Raitakari, O.T., M. Juonala, M. Kahonen, L. Taittonen and T. Laitinen et al., 2003. Cardiovascular Risk factors in childhood and carotid artery intima-media thickness in adulthood: The cardiovascular risk in young finns study. JAMA., 290: 2277-2283. DOI: 10.1001/jama.290.17.2277

Tam, C.S., K. Clement, L.A. Baur and J. Tordjman, 2010. Obesity and low-grade inflammation: A paediatric perspective. Obes. Rev., 11: 118-126. DOI: $10.1111 /$ j.1467-789X.2009.00674.x

Tanner, J., 1963. Growth at Adolescence. 2nd Edn., Blackwell, Oxford, pp: 325.

Tjonna, A.E., S.J. Lee, O. Rognmo, T.O. Stolen and A. Bye et al., 2008. Aerobic interval training versus continuous moderate exercise as a treatment for the metabolic syndrome: A pilot study. Circulation, 118: 346-354.

10.1161/CIRCULATIONAHA.108.772822

TSG, 2008. Healthy Eating, Active Living: An action plan to improve diet, increase physical activity and tackle obesity (2008-2011): The Scottish Government, Edinburgh.

TSG, 2009. Scottish Index of Multiple Deprivation: 2009 General Report. The Scottish Government, Edinburgh.

TSG, 2010. School Meals in Scotland, 2010. The Scottish Government, Edinburgh.

Twisk, J.W.R., H.C.G. Kemper and W.V. Mechelen, 2000. Tracking of activity and fitness and the relationship with cardiovascular disease risk factors. Med. Sci. Sports Exe., 32: 1455-1461. DOI: 10.1097/00005768-200008000-00014

Valle, M., R. Martos, F. Gascon, R. Canete and M.A. Zafra et al., 2005. Low-grade systemic inflammation, hypoadiponectinemia and a high concentration of leptin are present in very young obese children and correlate with metabolic syndrome. Diabetes Metab., 31: 55-62. DOI: 10.1016/S1262-3636(07)70167-2 